\title{
Proposed advanced training \& educational methodologies, for tanker \& gas industry
}

\author{
Wael Khattab ${ }^{1}$, Ibrahim El Attar ${ }^{2}$ \\ ${ }^{1}$ African \& Asian Affairs Program Manger, Arab Academy for Science \& Technology \& Maritime Transport \\ ${ }^{2}$ Head, Nautical Studies. Dept,. Port Training Institute, Arab Academy for Science \& Technology \& Maritime Transport
}

\section{Email address:}

waelmdkhattab@yahoo.com (W. Khattab), Ibrahim.elattar@pti-aast.org (I. E. Attar)

\section{To cite this article:}

Wael Khattab, Ibrahim El Attar. Proposed Advanced Training \& Educational Methodologies, for Tanker \& Gas Industry, International Journal of Materials Science and Applications. Vol. 2, No. 1, 2013, pp. 1-7. doi: 10.11648/j.ijmsa.20130201.11

\begin{abstract}
Oil and gas are considered to be among the world's most prized resources. Hence, no doubtfully, The oil and gas industry plays a significant role in the global economy. Petroleum itself is used for numerous products, in addition to serving as the world's primary fuel source. Furthermore, The processes and Technologies concerned in producing and distributing oil and gas are highly complex, capital-intensive and necessitate state-of-the-art technology, nonetheless , rather more importantly human resources operating these technologies in a safe efficient mode. Here arises main concern ! What will be ideal global unified education and training methodologies to be provided by Maritime education \& Training Institutes " MET for these labour in such critical rather indispensable industry? To ensure " Safer Seas \& Cleaner oceans" (IMO/ IMCO 1994). This paper will illustrate ideal training \& education methodologies to be delivered to these crews, in campus or rather on-board. Highlighting current conventions for promoting skills and inducing quality for such dedicated rather crucial industry.
\end{abstract}

Keywords: Oil And Gas, Maritime Education \& Training, Capital Intensive

\section{Introduction}

One of the key differences between STCW 95 and the previous Convention is the stress on competence rather than knowledge. STCW 95 stipulates in detail the required competences associated with different tasks, the knowledge and understanding required to perform them, methods for demonstrating competence and criteria for evaluating it.

Global standards for seafarer have been a major concern for the maritime industry that has lead to the birth of the STCW 78. It was expected that it would promote competence of seafarers. Consequently it was widely welcomed by the industry as it was the first convention ever to be delivered by the IMO setting global minimum standards for seafarers.

After quiet some time it was realized by the maritime society that the convention was not achieving its purpose. This was mainly because it lacked accuracy in its standards. In addition, implementation of the convention was left to the "satisfaction of the Maritime Administrations"; this resulted in different interpretations by various administrations, thus there was an immanent need for revision that resulted in the STCW 95.

After the implementation of STCW 95, and all member states have adopted and amended their curriculum to the new requirements through a transitional period of five years, yet no crucial evidence can be obtained with reference to major improvement to seafarer's competence due to many new tasks that remain unfinished to give full and complete effect to the convention globally. As the seven years period since 1997 has been both a success and failure, it appears now; that with new technologies introduced onboard (i.e. ECDIS, AIS, Integrated Bridge Navigation Systems, and Automation with respect to minimum safe manning onboard) makes a need to revise STCW, to keep the convention dynamic as it is supposed to be.

\section{The Hydro Carbon Industry, Trans- portation}

Realizing above table, shows no doubt decrease or non ascending tanker/ gas carries causality rate, one the nonetheless it is the aim of maritime society no doubt with modern technologies applied on board ship's today to arrive 
to zero causality rate. Nonetheless an out standing problem still lingers ! unifying of Maritime education \& Training curriculum and pedagogical affairs in All MET institutes globally. Hence the officer yet engineer regardless of any nationality can still perform as equal.

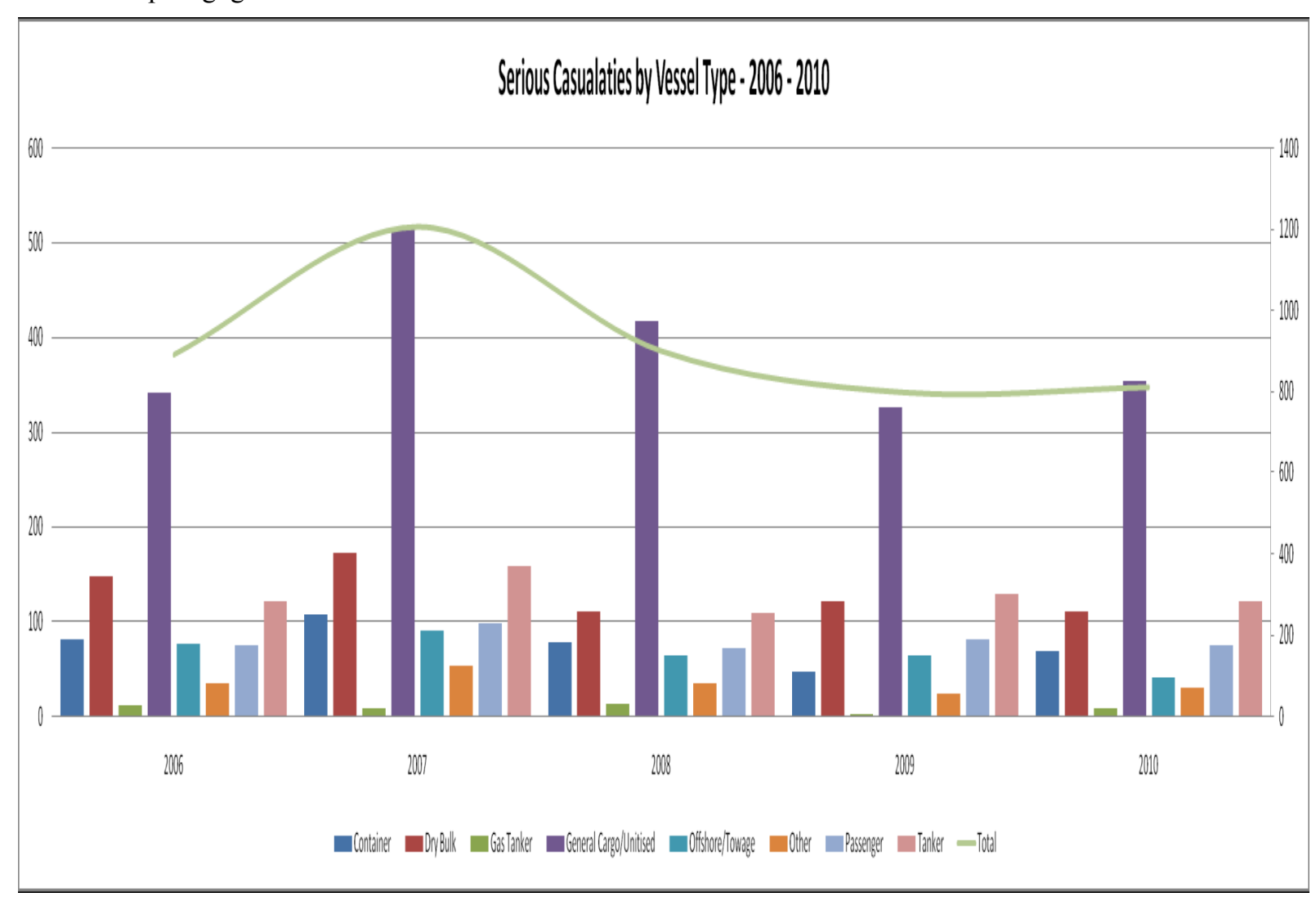

Source: Lloyd's List Intelligence 2012.

Nonetheless, social economical affairs might enable some to train perfectly, while others are deprived from proper training \& education.

Tankers, LPG, LNG, travel interregional water routes. Tankers are primarily the major haulers of oil a tank vessel as one that is constructed or adapted to carry oil or hazardous material in bulk as cargo or cargo residue. The earliest construction of tank vessels used single hulls.

There are various types of tankers: oil tanker, parcel tanker (chemical vessels), combination carrier (designed to carry oil or solid cargoes in bulk), and barges. In addition, there are international bulk chemical codes governing the safe transport of chemical cargoes providing various levels of protection against the uncontrolled release of substances that pose the greatest environmental risk.

Tank vessels are classified by the trade in which they normally operate over a period of time. The three most common categories are crude oil carriers, product carriers: which can carry clean (e.g., gasoline, jet fuel) and dirty (e.g. black oils): and parcel carriers (chemicals). Tankers tend to remain in one trade but market conditions can dictate a change, even though the process to change a vessel's trade involves extensive work.

Crude carriers are classed as either VLCCs (Very Large Crude Carriers) or ULCCs (Ultra Large Crude Carriers) and are designed to transport huge quantities of crude oil over many long and heavily travelled sea routes. The appropriate economies of scale depend on the area from which the oil is being shipped. In addition, "lightering," offloading or transferring oil from large tankers to smaller ones, a process which can move 1,000 barrels per hour: is used so that the smaller vessels can enter smaller ports that the larger vessels cannot.

Historically, most of the nation's tanker fleets were built as single-hull vessels, i.e., a single layer of steel made up the hull. As ships and barges is a major link in the country's oil transportation network, both for transporting crude oil to U.S. refineries and for transporting refined oil products to market, the Oil Pollution Act (OPA) of 1990 made extensive changes designed to make these shipments environmentally safer. One change requires the phasing out of all shipment of oil cargoes in single-hull vessels in U.S. waters from 1995 to January 1, 2015, with the oldest and largest vessels phased out first. After January 1, 2015, only double hull vessels may be used. There are also European standards in this area with the Regulation of the European Parliament and of the European Council/Commission on Legislative Documents amending Regulation EC No. $417 / 2002$ on the accelerated phasing-in of double-hull or equivalent design requirements for single-hull oil tankers.

One of the major concerns in the safe transport of bulk liquid cargos by tank vessel is the stress on the hull. Bend- 
ing in the form of sagging (concentration of weight in the mid section of the vessel causing the deck to be subjected to compression forces while at the same time the keel is under tension), hogging (concentration of weight at both ends of the vessel causing the deck to experience tensile forces while the keel is under compression), and shear force, which occurs when two forces act in opposite directions parallel to each other, such as at a bulkhead between an empty ballast tank and a full cargo tank. The weight or gravitational and buoyant action experienced on either side of the bulkhead causes the shear force phenomenon.

The development of the super tanker came about due to an array of factors including Middle East hostilities that led to the closure of the Suez Canal, nationalization of oil fields in the Middle East, and strong competition among international ship owners. VLCCs and ULCCs cover the most solitary trade routes, typically loading at offshore platforms or single-point moorings and discharging at designated lightering zones off the coast.5 As the demand is increasing for more crude oil and as more oil reserves are being discovered and developed in other areas such as the Caspian Basin, Latin America and the Middle East, the need for more tankers has grown

\section{The Recommended Change: (Train- ing Issues)}

\subsection{Current Programs}

In order to provide the graduates of a maritime institute with a thorough and suitable education that includes the professional, competent knowledge and skills necessary to be a competent mariner, the MET institutes need to periodically revise the content of their curriculum as per new technologies installed onboard and industry needs. According to Sears, F. (2003), "Unfortunately, we are not masters of our own curriculum", nevertheless, MET institutes should respond to the needs of the shipping companies, as the later is who employs their graduates if they feel that the graduates requires proficiency in a certain field. A good example would be the training on the use of Electronic Charts, as many shipping companies would necessitate that their Deck Officers have had the essential training ashore before joining on board as they have outfitted all of their vessels with ECDIS equipment.

Sears, F. (2003), further indicates that "On the other hand, it is very difficult to teach a topic that has little if any relevance, as both the students and the instructors recognize that the time spent mastering this subject is wasted." As an example, many nations continue to teach and test their deck license candidates on Radio Direction Finder fixes or how to obtain an OMEGA fix, an obsolete navigational aid and a skill that they will never use at sea in the pursuit of their profession!

Many major maritime nations such as the Netherlands represented by the "Willem Barentsz Maritime Institute" which the authors have had the privilege to visit have total- ly reduced the credit hours required to teach celestial navigation to a "by knowledge" situation, and non at the management level. As obtaining a proper celestial fix is subject to weather conditions and from the authers' personal experience, overcast skies persisted in some cases more than five days, while modern satellite navigation systems would operate properly in all weather conditions.

Some may argue that these skills must be always held in hand, in case of GPS or GMDSS systems failure. It is obvious to all persons in the maritime industry that for successful, proper, and economical vessel operations, definitely the reliability of these systems is required. This reliability is provided by the accuracy, punctuality and continuity regulated for GMDSS. Furthermore, most vessels now have more than one GPS receiver, as the cost is minimal also, the availability of portable GPS.

At this stage, the author's would take this opportunity to recommend that other maritime curriculum's such as the subject of maritime signalling should be deleted entirely as it is slow, limited in effective range, and frankly, with the elimination of a radio officer on board and infrequent use of signalling by officers, there is no need for such module.

\subsection{Training Subjects}

Training onboard adopted by the STCW 95 has its potential drawbacks because if training and assessment are to be done onboard, how Maritime Administration's are to supervise, monitors, and approves such exams while ship is at sea as it is required by the STCW 95? And, if assessment is to be carried out on board then who exactly will supervise the procedures, as Lima, K. (2000), states "if objective criterion is not applied, proficiency demonstration has the potential to become troublesome due to subjectivity of the demonstrations."

Furthermore, how do we expect heavily burdened officers to conduct training and assessment onboard while the issue of fatigue is continuously lingering on to be the major cause behind most maritime causalities. Accordingly the IMO and the ILO responded by setting standards for what is known to be the rest hours required for seafarers on board ships. Nevertheless, ship-owners criticized those rest hours, as Binnington, 2000, mentioned that rest hours adopted by STCW is seen somehow unreasonable, due to nature of work at sea. In addition no guidance on the format in which hours of rest records may be kept due to the nature of some shipping lines.

Furthermore, there are still variations on who should conduct the examinations, as in some nations examinations are conducted entirely by the national Maritime Administrations, while other nations MET institutes takes care of the examinations procedure. On the other hand it can be by both, or by an external body, also mentioned by Vanchiswar, S. (1999).

Wainbow, A. (2000), illustrates a very important point, that according to the code, seafarers are required to produce evidence every five years of having achieved basic safety training standards. Unfortunately this is done in two 
ways causing a debate to rise:

Some parties issue documents with five years expiry date. Hence, requiring seafarers to retrain every 5 years, while others takes it for granted that no expiry date is required providing adequate training is done on board. Then how can we globalize and harmonize MET if different standards are still applied?

STCW encourages vocational MET education and discourages academic education for onboard jobs. The consequences of that, is the knowledge of seafarers would be of a very limited scope. Hence it will not be easily for mariners to find jobs ashore. ZEC, D. and Pritchard, B. (2000).

Also it is required by the STCW 95 that there should be communications and submitting of reports to the IMO every five years in order to make sure that the adopting and implementing of a quality system by the national maritime administrations is always monitored.

Nevertheless, Winbow, A. (2000), comments on this point by saying "The communication of information is considered to be a bureaucratic one. Some of the parties' information has been voluminous, with much supporting information, and there has had to be much copying and forwarding". Some MET institutes unfortunately did the same.

Another out most important issue which is the tanker training and familiarization, though it is very important due to the special nature of those ships, and with due regard to the major pollution accidents that nations suffer from, such training requirements are not presented in the tabular form among other competencies. In addition, "the training requirements for passenger Ro-Ro ships applying to various seafarers and officers on board are somehow mixed." Winbow, A. (2000).

Equally important, unfortunately the STCW 95 somehow neglected in a way or the other the training requirements for ratings, as the majority of the new provisions in the revised STCW convention concern competence standards for officers.

\subsection{Training Standards}

However it can be argued that the ISM code insists on familiarization periods for new joiners in our case. Nevertheless, training for these systems is not always achievable for a mariner joining a vessel just prior to departure or a pilot boarding a vessel, also training for different designs of equipment ashore is difficult financially (equipping a training centre with different systems). Seafarers always find themselves required to use at sea different systems than those they are trained to use, however manufacturers can provide assistance that guide specific training by supplying adequate tools as software and complete manuals, which is not the case.

In addition, the STCW did not provide any specifications for simulators required training, except for Radar/ARPA simulators. Also with the rapid development of technology, the wide use of GMDSS (Mandatory), ECDIS, AIS, and VDR onboard ships, there is no criteria for training men- tioned in STCW 95. There are many challenges encountered when we address and assess practical training needs for mariners in using technology based systems aboard, in order to be able to use technology based systems to make safe decisions.

There is the issue of who should bear the costs of developing equipment specific training, however, Computer Based Training (CBT), Computer Aided Learning (CAL), and most importantly Distance Learning (DL) which is defined by the American institute for distance learning as it is " the bridge that covers the time and distance gap between learners and tutors" can provide the required modules for equipment use onboard or even ashore before joining the vessel. Accordingly this can aid to improve the training and familiarization situation. Most importantly, it would be worthwhile to mention that technical manuals were reported to be insufficient training tools.

Unfortunately Training on new technology is in many cases only focused on the use of the equipment and not on using the technology to assist the decision making process. The wide impact from this procedure will be handicapping the capabilities of seafarers.

ECDIS and AIS are no doubt equipments of adding values that would improve the operations when used by well trained officers who understand how to manage and evaluate information. However, the same equipment can cause a disaster no doubt when used by an officer without trained skills to perceive and prioritize the information at hand. Nevertheless, there are endless arguments that over reliance upon them have to be avoided and their use has to be balanced with other appropriate means.

\section{Recommended Solutions}

As per International Federation of Shipmasters' Associations (IFSMA), 2003, "Cascade training for onboard technology based systems (engineering, cargo, navigation, communication) may not be adequate to ensure safe operation", as there is no sufficient time to train, also the officer providing the training may not fully understand the system themselves, or that the officer may not be sufficiently capable to train or assess.

Another new technology which is applied on many modern ships today is the Integrated Navigation system (INS) or, Integrated Bridge system (IBS), in an attempt by shipowners to save the operating costs by appointing minimum crew on board their ships "minimum manning" and not "safe manning". Though it have its recognized pros such as : better use of ships technology, advanced team work, financial savings, yet it has its major recognized cons, briefly it can be said that the watch office became heavily burdened and stressed, with the must of monitoring various monitors, gauges and variable alarm responses. Above all there is an absolute need to fully train such officers to handle such equipments, yet we find no training standards available in the STCW 95. 


\section{Tankers Safe Training for Liquid Cargo Operations}

Safe Cargo is a flexible training simulator that provides real-time simulation of the thermodynamic and fluid properties of the liquids and gases involved, together with the process control systems used in the storage and handling of potentially hazardous bulk liquids.

The system is primarily intended to be used for the training of personnel involved with the handling of bulk liquids and In order to facilitate modern training for seafarers, many curriculum should be revised, as much valuable time is wasted on studying and training on obsolete topics with reference to modern technologies applied on board today.

\section{STCW compliance 2012}

The International Convention on Standards of Training, Certification and Watchkeeping for Seafarers (STCW) aims to achieve for the shipping industry what increased technology has so far failed to deliver, namely a reduction in the $80 \%$ of accidents on board ship attributable to human error. Proper training and evaluation can make a real difference to these damning statistics.

Major revisions to the International Convention on Standards of Training, Certification and Watch keeping for Seafarers (the STCW Convention), and its associated Code have been adopted at a Diplomatic Conference in Manila which the author's were privileged to attend in the Philippines, thereby ensuring that the necessary global standards will be in place to train and certify seafarers to operate technologically advanced ships for some time to come.

The amendments, to be known as "The Manila amendments to the STCW Convention and Code" are set to enter into force on 1 January 2012 under the tacit acceptance procedure and are aimed at bringing the Convention and Code up to date with developments since they were initially adopted in 1978 and further revised in 1995; and to enable them to address issues that are anticipated to emerge in the foreseeable future.

Amongst the amendments adopted, there are a number of important changes to each chapter of the Convention and Code, including:

-Improved measures to prevent fraudulent practices associated with certificates of competency and strengthen the evaluation process (monitoring of Parties' compliance with the Convention);

- Revised requirements on hours of work and rest and new requirements for the prevention of drug and alcohol abuse, as well as updated standards relating to medical fitness standards for seafarers;

- New certification requirements for able seafarers;

- New requirements relating to training in modern technology such as electronic charts and information systems (ECDIS);

- New requirements for marine environment awareness training and training in leadership and teamwork;
- New training and certification requirements for electrotechnical officers;

- Updating of competence requirements for personnel serving on board all types of tankers, including new requirements for personnel serving on liquefied gas tankers;

- New requirements for security training, as well as provisions to ensure that seafarers are properly trained to cope if their ship comes under attack by pirates;

- Introduction of modern training methodology including distance learning and web-based learning;

- New training guidance for personnel serving on board ships operating in polar waters; and

- New training guidance for personnel operating Dynamic Positioning Systems.

The author's suggested that the successful closure of the Conference should be seen as marking the beginning of strenuous efforts at three levels: first, to commence, at the earliest possible opportunity, work to translate the revised STCW requirements into national regulations - with the aim of expediting their implementation; second, to deliver, as appropriate, technical assistance through IMO's Integrated Technical Co-operation Programme - with the aim of familiarizing STCW Parties with the revised requirements, and to provide useful technical advice on the STCW Convention and the STCW Code as a whole; and third, to initiate action, as may be necessary, to ensure the full and effective implementation and rigorous enforcement of the revised STCW Convention and Code when the amendments come into force on the agreed date of 1 January 2012,"

Delivery of Training On- Board, Keeping STCW Requirements sharp:

Distance learning :

Definitions

The United States Distance Learning Association (USDLA), founded in 1987, defines distance learning as "The acquisition of knowledge and skills through mediated information and instruction, encompassing all technologies and other forms of learning at a distance."

"The term distance learning (DL), refers to a teachinglearning arrangements in which the learner and teacher are separated by geography, time, and, technology (i.e. voice, video, printed data, CBT, CAL, CAI), \& Internet is used to bridge the instructional gap". Willis (2001). Supporting the above, Garrison (1989) concedes that the main characteristic of DL is the non-contiguity of the teacher and learner.

\section{Role of Met Institutes:}

Met Institutes \& DI:

Most MET institutions are using CBT as part of their educational process. However, some people fell that DL is the answer for problems related to maritime institutes such as "Non permanent attendance at courses, seminars \& laboratories" Dinu (2000).

Lewarn (2001) states that, “ If MET providers do not start developing their own future in a coherent, structured $\&$ systematic way, then others will impose the change on them." Leaving MET providers, to think and react to the 
aspects of change.

\section{Challenges to MET:}

It is now left for education institutions to adapt to new techniques in teaching. DL is not a theory or a phenomenon that will fade away. On the contrary, the technology revolution is here to stay. Hence, traditional classroom teachers should also smoothly adapt to the new technologies other than resisting them. This will ensure them a place in the coming world of DL.

"In the $21^{\text {st }}$ century, the maritime education and training community finds itself facing an explosion of new developments in communication tools, simulation, software training programs and expanding use of computers linked to the Internet and the Web" Muirhead (2002).

Currently education is becoming globalized, and it is treated as a commodity, where the customer is the student. Lewarn (2001) states that globalization of education will lead to a quick downfall of the traditional education, \& will induce a giant leap towards borderless education.

"Maritime educational institutions also face the challenge today of utilising new technology, communications and teaching methodologies in order to enhance the learning environment of tomorrow. Whether offering on-campus or off-campus courses, "computers and IT resources are rapidly becoming indispensable delivery tools" Muirhead (2002).

For MET institutions, to meet the challenge, they must adopt the new techniques and hopefully not on the account of quality. Muirhead (2000) states that the "quality of academic standards \& credibility is dependant upon many factors. In today's world, provision of up-to-minute computing and Internet services is crucial for education.

Tradionally, maritime educators have focused on the technical aspects of their systems, but with the current strong changes, providers of MET will need to take on these changes in order to maintain their role $\&$ be able to reserve a seat among others in the educational world, otherwise, they will simply perish.

One important aspect for DL, is that it can provide lifelong learning. Hence changing what was known to be "just in case" to "just in time" which means life long learning (Williams, 1999 \& Lewarn, 2001). This can only be provided through DL.

However for DL to be fully adopted and implemented there is a need for legal guidelines set and recognized by the IMO. This would avoid conflict between providers and maritime administrations. A clear-cut definition of the contents of knowledge and skills constituting the DL subject should also be clarified by IMO.

\section{Conclusion}

Safety on board tankers requires more courses as tanker safety, advanced fire fighting and tanker operation course which require simulator for training tanker officers and engineers.

Different interfaces result in increased training needs which are unpractical in many circumstances, accordingly if standardization of interfaces and symbols is not achieved, training for specific type is required to achieve safe operations.

STCW 95, in educational terms, is a welcome change, as it should finally bring maritime education into line with accepted educational practice and needs of the industry. Nevertheless, the proper and up to date implementation lays in the hands of parties to the convention. Furthermore, requirements for training on the use of such electronic systems must be included and detailed in the STCW, in order to emphasis their use in assisting the decision making process rather than simply the operation of the equipment itself.

\section{References}

[1] Bennet. S. (2000), Implementation of STCW 95 from the perspective of the international shippin industry. Proceedings of the eleventh IMLA conference on Maritime Education and training. August 2000. Malmö Sweden.

[2] Binnington J.R. (2000) STCW the Debate. The Baltic company news 2000 .

[3] Germanchir Lloyd (2002): STCW: Responsibilities of Administrations. Retrieved from the World Wide Web on 11/1/2004 from: http://www.germanlloyd.de/infoServices/seminars/stcw/resp onseadmin.html.

[4] Hork. J. (2003) STCW, Quality assurance and IMO model courses. Unpublished lecture handout. World Maritime University, Malmo, Sweden.

[5] Hunter C (1998), The STCW dead line approaches. Bimco Bulletin volume 91 NO-6.

[6] International Maritime Organisation. (2001). STCW 95. London: Author.

[7] IMO.(2010): STCW White List. Retrieved from the World Wide Web on 12/9/2011 from: http://www.imo.org/Newsroom/mainframe.asp?topic_id=70.

[8] ISF (2009): Publication of the IMO "white list". Retrieved from the World Wide Web on 1/2/2004 from: http://www.marisec.org/isf/isfkey2001/publicationofwhitelis t.htm.

[9] ISF (2009): STCW 95: the final countdown. Retrieved from the World Wide Web on 10/12/2003 from: http://www.marisec.org/isf/isfkey2002/STCW.htm.

[10] ISF (2009): Implementing STCW 95 . Retrieved from the World Wide Web on 10/12/2003 from: http://www.marisec.org/isf/isfissue/impstcw.htm.

[11] Lima B.K (2000), Impact of STCW on US Maritime Academies. History of STCW \&IMO. Proceedings of IAMU inaugural general assembly. 26-29 June 2000. Istanbul. Turkey.

[12] Muirhead .P. (2000): Making STCW works- the need for global cooperation. BIMCO review 2000. 
[13] Muirhead.P. (2003): Maritime education \& training \& STCW 95. Slides, notes and readings. Unpublished lecture handout. World Maritime University, Malmo, Sweden.

[14] Pritchard. B \& Zec. D (2000), MET- academic approach vs. STCW 95. . Proceedings of the eleventh IMLA conference on Maritime Education and training. August 2000. Malmö Sweden.

[15] Sears, D. F. (2003), "A Perspective of Seafarers Training" Proceedings of the 3rd IAMU Conference. 28 September 2003 Alexandria, Egypt.

[16] Sub-Committee on Standards on Training and Watchkeeping, 34th session, (2003). "Issues for training seafarers resulting from the implementation of onboard technology" submitted by International Federation of Shipmasters' Asso- ciations (IFSMA),

[17] Marine Casualty Profiles, International Maritime Statistics Forum, Hong Kong 31stMay 2011.

[18] http://www.imo.org/KnowledgeCentre/ShipsAndShippingF act-

sAndFgures/Statisticalresources/Casualties/Documents/Wall $\mathrm{y} \% 20$ Mandryk $\% 20 \% 20$ Lloyds $\% 20$ List $\% 20$ Intelligence $\% 20$ $\% 20$ Shipping\%20Casualty\%20Profiles\%20ISMF\%202011. pdf.

[19] Willis, B. (2001). Guide \#1,2,3 \&11: Distance education: An overview. University of Idaho.

[20] Retrieved April 5, 2002 from the World Wide Web: www.uidaho.edu/evo/dist $1 / \mathrm{html}$. 